This work is licensed under a Creative Commons Attribution 4.0 International License.

Ovaj rad dostupan je za upotrebu pod međunarodnom licencom Creative Commons Attribution 4.0.

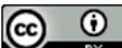

Kristina PETERNAI ANDRIĆ

UDK 82.0

Filozofski fakultet

Sveučilišta Josipa Jurja Strossmayera u Osijeku

Lorenza Jägera 9, HR - 31000 Osijek

kpeterna@ffos.hr

Viktoria KLUISER

Ružina 51b, HR - 31327 Vardarac

viktoriakluiser@gmail.com
Pregledni članak

Review Article

Primljeno: 19. travnja 2017.

Prihvaćeno: 21. lipnja 2017.

\title{
DJELOKRUG KOGNITIVNE NARATOLOGIJE
}

\section{Sažetak}

Promatrajući ju u nizu srodnih koncepata - među kojima su kognitivna poetika, kognitivna lingvistika, kognitivizam, evolucijska književna teorija - rad tematizira kognitivnu naratologiju kao smjer razvijen unutar postklasične i novih naratologija. Naznačuje se njezin opseg i doseg unutar kognitivne znanosti, ali se također tematiziraju koncepti poput sheme, okvira, pripovjednosti, parabole i drugi što mogu utjecati na razvoj i preoblike unutar kognitivne naratologije.

Ključne riječi: kognitivna naratologija, kognitivna poetika, shema, okvir, pripovjednost

Naratologija je kao znanost o pripovijesti ${ }^{1}$ uvedena i definirana pod zaštitom tada već etabliranog strukturalizma krajem šezdesetih godina dvadesetog stoljeća. U tom se užem značenju pojam naratologije rabi i danas, ali se naratologijom također određuje gotovo neomeđena disciplina što pokriva ukupno proučavanje i teoriju pripovijesti od njezinih početaka do danas. ${ }^{2}$ Suvremena naratologija

Formulacija se prvi puta javlja u knjizi Tzvetana Todorova: La science du récit u La Grammaire du Décaméron. U domaćoj književnoj znanosti récit se prevodi i kao pripovjedni tekst i kao pripovijest.

2 U domaćoj se književnoj znanosti uz pojam naratologije u širem smislu, u dijelom podudarnom značenju, paralelno rabi pojam teorija pripovijedanja. Terminoloških je nedosljednosti u naratološkim pristupima, i književnoj teoriji uopće, mnogo. 
razgranata je u brojne analitičke, metodološki heterogene i često pragmatične modele orijentirane prije svega na kontekst, a ne (kao klasična naratologija) na samu pripovijest i uvriježeno se određuje pojmom postklasična ili nove naratologije. ${ }^{3} \mathrm{U}$ formalnom su smislu postklasična i nove naratologije u znanost o književnosti uvedene devedesetih godina dvadesetog stoljeća, međutim obilježja novog smjera javila su se već početkom osamdesetih. ${ }^{4}$ Kao što primjećuje Herman: „prilagođujući mnoštvo metodologija i perspektiva - feminističku, bahtinijansku, dekonstrukcijsku, teoriju čitateljskog odgovora, psihoanalitič$\mathrm{ku}$, historijsku, retoričku, filmsko-teorijsku, računalnu, diskurzivno-analitičku i (psiho)lingvističku - pripovjedna teorija prolazi ne pokop i pokopavanje nego prije ravnomjernu, ponekad čak naglu metamorfozu“ (Herman 1999: 1), što konačno vodi tomu da se o naratologiji govori u pluralu: „naratologija je razgranata u naratologije“ (Herman 1999: 1). Prefiks "post“ stoga ne označava prekid sa strukturalističkim teorijama, nego je riječ o ponovnom oživljavanju i metodološkoj nadopuni, ${ }^{5}$ jer novi pristupi preoblikuju analitičke metode, pretpostavke i ciljeve klasične naratologije. Različite pravce postklasične i novih naratologija danas je moguće zapaziti pod velikim brojem naziva: kognitivna naratologija, retorička naratologija, prirodna naratologija, neprirodna, postmodernistička naratologija, kulturalna naratologija, etička, politička, postkolonijalna, psihoanalitička, historiografska ili povijesna, naratologija mogućih svjetova, odnosno, cyber naratologija, pravna, feministička, rodna, queer, transgenerička, psihometrijska naratologija i druge.

Kognitivna naratologija istodobno je odvjetak kognitivne znanosti ${ }^{6}$ kao interdisciplinarnog i multidisciplinarnog područja što se tiče prvenstveno istraži-

3 Polemika se javila neposredno nakon Hermanova plasiranja pojma u književnoteorijski diskurs. Pojam postklasične naratologije na međunarodnoj je razini danas usvojen, iako ne bez zadrške. Manji dio teoretičara rabi navodnike pri upotrebi, a dio teoretičara uopće ne vidi dio suvremenih naratoloških istraživanja pod njezinim „kišobranom“ (usp. Pier 2011).

4 David Herman detektira početke postklasične naratologije u tekstu Davida Lodgea (1980) u kojemu kroz pluralan pristup „Mački na kiši“ Ernesta Hemingwaya uspostavlja tripartitni sustav što uključuje narativnu gramatiku, narativnu poetiku i retoriku priče. Lodge ispituje „u kojoj su mjeri priče to što jesu ne samo zbog njihove forme, nego zbog kompleksne međuigre između pripovjednih oblika i konteksta pripovjedne interpretacije“ (Herman 1999: 8). Uopće o razvoju naratologije usp. Nünning (2003), Meister (2009), Peternai Andrić (2014).

5 O novim pristupima Herman kaže to da se „radije promišljaju konceptualna podupiranja i ponovno procjenjuju opseg primjenjivosti“ (Herman 1999: 3). S tezom prema kojoj potpuno odbacivanje strukturalističke naratologije radi više štete nego koristi slažu se Herman i Vervaeck (2005). 
vanja računalnih znanosti, posebno umjetne inteligencije, biologije, neuroznanosti, ali i društvenih i humanističkih disciplina među kojima su psihologija, lingvistika, filozofija, antropologija, sociologija pa i književna teorija. Korijeni kognitivne znanosti sežu u istraživanja teorije uma utemeljene na računalnim procesima iz pedesetih godina dvadesetog stoljeća da bi se kao zasebna znanost etablirala dvadesetak godina kasnije kroz istraživanja različitih mentalnih stanja, pritom usmjerena na odnos ljudske svijesti i ishode spoznajnih procesa u kulturi što ih čine jezične i druge simboličke tvorevine (usp. Biti, Marot Kiš 2014). Uslijed razvoja interesa prema kognitivnim fenomenima (percepcija, zaključivanje, mišljenje, emocije, jezik i drugo) šire se područja uključenih znanstvenih disciplina do te mjere da se govori o kognitivističkom obratu u znanosti i razvoju jednog od njezinih odvjetaka - kognitivne poetike. Pojam kognitivna poetika odnosi se na novouspostavljeni okvir koji u suradnji s neuroznanstvenim uvidima jezik promatra kao funkcionalni izdanak spoznajnoga procesa, što uključuje njegovu književnu i svakodnevnu uporabu, ali i kulturno uvjetovane osobitosti. ${ }^{7}$ Kognitivna istraživanja u književnoj znanosti u najširem se smislu mogu opisati kao analiza književnih tekstova usmjerena prvenstveno na um i procese mišljenja, uključujući kulturne dosege i odnos pojedinca ili zajednice spram emocija, a samu suradnju između kognitivne znanosti i istraživanja književnosti moguće je pratiti u posljednja gotovo četiri desetljeća, uzimajući u tom smislu studiju Georgea Lakoffa i Marka Johnsona „Metafore koje život znače“ iz 1980. godine ${ }^{8}$ kao ključnu za ostvarivanje užega uzajamnoga povezivanja i koordinirane interdisciplinarne suradnje, da bi se kognitivni studiji kao zasebna grana književne teorije institucionalizirali u raspravi na „Conference of the Modern Language Association“ u SAD-u 1998. godine. Kognitivna lingvistika u skladu s tim daje ključan poticaj razvoju kognitivne poetike. Rana istraživanja na području kognitivne lingvistike usmjerila su pozornost na proučavanje kon-

znanost uveden je nastojanjima Christophera Longueta-Higginsa sedamdesetih godina dvadesetog stoljeća.

„Od kada se 1980. godine pojavila utjecajna knjiga Georgea Lakoffa i Marka Johnsona „Metafore koje život znače", književni znanstvenici ohrabreni su idejom kognitivne poetike, odnosno, sustavne teorije uma u kojoj književnost nije samo periferna nego središnja za razumijevanje ljudske psihologije." (Vandaele, Brône 2009: 1f) Kognitivna poetika se prema Peteru Stockwellu $(2002,2007)$ može smjestiti unutar domene stilistike. „Kognitivna poetika, primjena kognitivne znanosti u smislu rasvjetljavanja književnog istraživanja, sazrijeva kao disciplina. U radu se tvrdi da se kognitivna poetika najbolje očituje u najnovijem razvoju progresivne evolucije stilistike." (Stockwell 2007: 135)

8 Monografiju „Metaphors We Live By“ s engleskoga je na hrvatski prevela Anera Ryznar, a objavljena je 2015. godine. Jednom riječju, Lakoff i Johnson tvrde da su metafore koje rabimo pri strukturiranju životnog iskustva univerzalne. 
ceptualne metafore, zatim slijedi konceptualna integracija kao „logičan slijed, ali ujedno i kao nadopuna Lakoffove (Lakoff, Johnson 1980, Lakoff 1987) dvodomenske teorije konceptualne metafore i metonimije (...)“ (Belaj, Tanacković Faletar 2006: 152). George Lakoff, Mark Turner, Mark Johnson, Len Talmy, Gilles Fauconnier i drugi usmjerili su zanimanje prema područjima koja su smatrana tradicionalno presudnima za istraživanja književnosti (kao što su metafora, pripovijest, lik, kontekst, značenje i druga), a što je rezultiralo shvaćanjem „svakodnevnoga uma“ kao književnoga (usp. Vandaele i Brône 2009). Riječju, kognitivni znanstvenici počinju se udaljavati od pojmova umjetne inteligencije, teorije jezika i psiholoških modela tvrdeći da su konceptualni procesi utemeljeni u ljudskom iskustvu ujedno neuralni i kognitivni procesi, prema tome omogućuju percepciju, kategorizaciju pa i upotrebu jezika.

Kroz navedene procese i poticaje oblikuje se i kognitivna naratologija, na ovaj način revolucionarizirana pa i pomlađena kao istraživački program (usp. Stockwel 2007). Pristupe koji se mogu ubrojiti u domenu kognitivne naratologije opisuje zajednički interes spram mentalnih stanja, sposobnosti i dispozicija što omogućuju, odnosno utemeljuju, pripovjedno iskustvo. Kognitivna naratologija mogla bi se sažeto odrediti kao proučavanje pripovjedne prakse vezane uz um, gdje god i na koji god način se te prakse odvijale. Po svom je opsegu transmedijalna jer se ne bavi isključivo prepletom pripovijedanja i uma u tiskanim tekstovima, nego zahvaća sve oblike pripovijesti i sve medije, što podrazumijeva da se referira na vezu uma i pripovijesti u svim pripovjednim medijima od tiskanog teksta, interakcije uživo ili licem u lice (konverzacijska interakcija), kroz kinematografiju, radio, televiziju... do računalom posredovanoga virtualnoga iskustva i drugih pripovjednih medija.

Kognitivna naratologija određuje se dakle kao područje za um relevantnih aspekata pripovjedne prakse, nevezano za to gdje se i kako te prakse odvijaju. Zanima se za intelektualnu i emocionalnu stranu procesuiranja pripovijesti što, dakako, nije ograničeno na književno pripovijedanje, nego obuhvaća kategoriju pripovjednosti u najširem smislu riječi. ${ }^{9}$ Perspektiva važnosti uma može se proučavati u odnosu na mnogostruke elemente uključene u strukturu i interpretaciju pripovijesti: od aktivnosti pripovjedača pri proizvodnji pripovijesti, do načina na koje recipijenti stvaraju smisao pripovjednoga svijeta potaknu-

Na način kako to rabi Monica Fludernik (1996): pripovjednost koja predstavlja antropološku kompetenciju u svom izvornom obliku. 
ti pripovjednim prikazom i kognitivnim stanjima samih književnih subjekata (književnih likova ili karaktera). Stajalište o vezi uma i pripovijesti nadaje se kroz dimenzije načina funkcioniranja priče (pripovijesti) kao domene interpretacije, zatim kao sredstva za stvaranje i dohvaćanje iskustvenoga smisla, odnosno izvora za strukturiranje i shvaćanje svijeta kao instrumenta strukturiranja vlastitoga iskustva. Herman kognitivnu naratologiju određuje kao poddomenu unutar postklasične naratologije, ukazujući na njezin rast unutar postklasične i novih naratologija općenito, upozorava na to da je potrebno tu teoriju promatrati kao poddomenu unutar cjelokupne kognitivne znanosti. ${ }^{10}$ Tako smještenu kognitivnu naratologiju treba razlikovati zbog mogućih konotacija od termina kognitivizam, ${ }^{11}$ ali i od evolucijske književne teorije koja tvrdi da geni određuju pravce evolucijske paradigme, načine na koji ljudski um opaža i razvija se (usp. Spolsky 2002).

Teoretičari koji se bave kognitivnom naratologijom u svoja su istraživanja uključili i prilagodili različita sredstva i metode za objašnjavanje, opis i analizu u interdisciplinarnom smislu (lingvistika, semiotika, računalna znanost, filozofija, psihologija). Naziv kognitivna naratologija u uporabi je devetnaestak godina i njegova prva primjena pripisuje se Manfredu Jahnu (usp. Jahn 1996), međutim pitanja i promišljanja obuhvaćena pojmom mogu se pratiti već kroz ranija istraživanja. Tako se kao preteče kognitivno-naratoloških istraživanja mogu razmotriti tekstovi nastali početkom sedamdesetih: Wolfganga Isera, Hansa Roberta Jaussa, Jane P. Tompkins i drugih, nastali u domeni književnih istraživanja usmjerenih pitanjima recepcije i čitateljskoga odgovora. Na području kognitivne psihologije i umjetne inteligencije došlo je do naglašavanja i razvijanja hipoteza vezanih za kognitivističku osnovu stvaranja i razumijevanja priča. Kao središnja preokupacija takvih psihologijskih istraživanja javljaju se među ostalim kognitivne mape, odnosno unutarnji modeli prostorno strukturiranoga okruženja, zatim sheme (schemata) što se definiraju kao mentalne reprezentacije ili

$10 \quad$ Narratology as a cognitive science. Usp. Herman (2000).

11 Kognitivizam (engl. cognitivism) odnosi se na stajalište da se um može reducirati na tijelom neuvjetovane, tj. bestjelesne mentalne manifestacije, odvojene od okruženja pri djelovanju i interakciji. Herman i drugi argumentiraju da stavljanjem naglaska na način rada i utjecaj uma, te njegovo funkcioniranje kroz domenu priče ne povlači za sobom razdvajanje, zagovarano kroz kognitivizam, mentalnih reprezentacija te socijalnog i materijalnog okruženja što pomaže oblikovati, pa i djelomično ustrojiti, um kao takav. Nasuprot tome, znanstvenici koji proučavaju vezu uma i pripovijedanja mogu proučavati i proces utjecaja kulturnih pripovjednih praksi na ljudska situirana mentalna stanja, kapacitete i tendencije. Usp. Herman (2013). 
okviri. ${ }^{12}$ Sheme kasnije bivaju podijeljene na dinamične i statične reprezentacije znanja: dinamičnima odgovaraju scenariji (scripts) što predstavljaju stereotipizirane sljedove događaja, a statičnima odgovaraju okviri (frames) i odnose se na stereotipizirana stanja stvari ili situacije (usp. Herman 2000). Slijedom toga Herman (2013) spominje djelovanje Rogera C. Schanka i Roberta P. Abelsona, znanstvenika koji su istraživali kako stereotipno znanje umanjuje kompleksnost i trajanje obrade zadataka, uključujući interpretaciju pripovijesti, sve kroz koncept scenarija i okvira, tipova reprezentacije znanja što omogućuju memorijsku pohranu očekivanoga slijeda događaja ili aktivnosti.

Budući da pripovijest dolazi u interakciju i ostvaruje se u skladu mentalnim sposobnostima čitatelja, s njegovim sjećanjima, emocijama i uvjerenjima, za razumijevanje procesa stvaranja čitateljskog iskustva potrebno je u razmatranje uključiti i kontekst. Prvi korak u smjeru uključivanja iskustvenoga konteksta u kognitivnu naratologiju jest upravo kroz teoriju sheme. „Sheme su kognitivne strukture koje predstavljaju općenito znanje, odnosno strukture što ne sadrže informacije o pojedinim tijelima, slučajevima ili događajima, već radije o svom općem obliku." (Alexander, Emmott http://www.lhn.uni-hamburg.de/ article/schemata) Budući da su u pripovijesti pojedinosti često izostavljene, recipijent se koristi shemama da bi nadoknadio te praznine. ${ }^{13}$ Pojam sheme često se upotrebljava paralelno s pojmom okvir, pri čemu se referira na prikaz znanja relativno statičnih objekata i odnosa, nasuprot reprezentaciji dinamičnih, temporalnih procesa ili scenarija. Shodno tomu, scenariji proizvode očekivanja o tome kako će se određeni slijed događaja odvijati, dok sheme stvaraju očekivanja o mogućem načinu strukturiranja domene iskustva u određenom trenutku u vremenu (usp. Herman i dr. 2005: 666). Kao prethodnika takvog tipa mišljenja, Herman (1997) navodi teze Dennisa Mercadala za kojega je scenarij opis očekivanoga načina na koji će se slijed događaja razvijati ili razmotati. Scenarij je sličan okviru u smislu da predstavlja skup očekivanja. Okvir se razlikuje od scenarija u smislu da odražava točku u vremenu, dok scenarij prezentira događanje u vremenskome slijedu. Shema je pak termin rabljen u psihologiji i referira na memorijski uzorak koji ljudi upotrebljavaju za interpretaciju trenutačnih

12 Navedene mentalne reprezentacije bilježe sistematski strukturirane odnose u kategorizirana iskustva. Usp. Alexander, Emmott (2011).

13 Pojam shema u područje kognitivnih znanosti ušao je preko psihologije i filologije. Prvi puta rabljen je tridesetih godina dvadesetog stoljeća, paralelno u psihologiji i teoriji književnosti, ali je u širi opticaj ušao sedamdesetih kroz izučavanja umjetne inteligencije. Usp. Alexander, Emmott (2011). 
iskustava. Kao primjer međuodnosa tih koncepata može poslužiti odlazak u pub u Velikoj Britaniji, što navodi Stockwel (usp. Stockwel 2002 i 2007). Scenarij puba sastoji se od elemenata poput šanka, ljudi što stoje za šankom ili stolovima, piva, boca, čaša i drugog. Taj se scenarij sastoji i od određenih procedura koje se rabe za naručivanje pića, tako je u slučaju puba u Britaniji karakteristično naručiti piće za šankom i odmah ga platiti. Procedura se sastoji od iskaza karakterističnih za naručivanje, od mjesta na koje se može sjesti i ponašanja koje priliči takvom scenariju. Scenariji se luče iz iskustva i ako osoba odluči posjetiti novi pub aktivirat će poznati scenarij, te znati točno što se očekuje i što može činiti i očekivati u danoj situaciji. Scenarij je prema tome sociokulturni mentalni protokol za snalaženje u situacijama. Na primjer, francuska ili belgijska obitelj zbog greške u primjeni scenarija može čekati za stolom u pubu da ih konobar posluži, ukoliko ranije nisu imale iskustva s britanskim pubovima. Bez saznanja o tome što određeni scenarij uključuje te primjenjujući svoj scenarij za slične prilike, dakle scenarij koji uključuje konobare i posluživanje za stolom, kao i plaćanje netom prije odlaska, umjesto za šankom pri naručivanju, pojedinac se može naći u neugodnoj situaciji. Scenarij odlaska u pub predstavlja situacijski scenarij (situational scripts), koji se rabi pri uobičajenim iskustvenim događajima poput odlaska u restoran, na vlak, rođendansku zabavu ili rad u vrtu. Kao drugi model, može se govoriti o osobnom scenariju (personal scripts), što se odnosi na znanje o tome kako biti suprug, supruga, kako se obratiti nepoznatoj osobi i slično. Naposljetku tu su i instrumentalni scenariji (instrumental scripts) koje rabimo na primjer pri uključivanju računala, paljenju vatre, čitanju i slično. Riječju, scenariji uključuju ranije planove, a planovi se odnose na uopćene konceptualne procedure poput druženja, na primjer, a što prelaskom u rutinu postaje scenarij.

Književne sheme (literary schemas) prema Stockwelu predstavljaju višu razinu konceptualne strukture koja organizira način našega čitanja unutar književnoga konteksta. Pri tome ukazuje na tri različite domene u kojima funkcionira, a podrazumijeva shemu svijeta (world schema), tekstne sheme (text schemas) i jezične sheme (language schemas). Prve sheme odnose se na kontekst, druge predstavljaju naša očekivanja o načinu pojavljivanja prvih shema u smislu strukturne organizacije i slijeda, dok treće sadržavaju našu ideju oblika prikladnoga jezičnog strukturiranja i stila (Stockwel 2002: 77-78).

Herman nudi tezu prema kojoj se um oslanja na velik broj iskustvenih repertoara, statičnih (shematičnih i okvirnih) i dinamičnih, nalik scenarijima (Herman 
1997: 1047). Ranija iskustva pohranjena u sjećanju oblikuju svojevrsni strukturirani repertoar očekivanja s obzirom na iskustvo koje će uslijediti ili je upravo u nastajanju. Statični repertoar omogućuje razlikovanje na primjer stolice od stola, a dinamični, poput navedenoga scenarija odlaska u pub, omogućuje da vršimo razlikovanje pri odlasku na pokop od, na primjer, odlaska na rođendansku zabavu. Za izvođenje složenijih zadataka potrebno je aktivirati više od jednoga scenarija. Također je potreban pristup mnoštvu scenarija za razumijevanje teksta ili diskursa, jer uslijed nedostatka stereotipnih scenarija čitatelji ne bi bili u mogućnosti izvesti osnovne zaključke iz tekstualnoga predloška. ${ }^{14}$ Takav pristup može potencijalno rekonceptualizirati teorije recepcije suprotstavljajući dijeljene i idiosinkratične strategije čitanja na pomak žarišta s interpretiranja konvencija na opće i temeljne mehanizme procesa obrade što daju tim konvencijama jačinu i opseg primjenjivosti. Kognitivna naratologija donosi pomak u pristupu teorija shema u smislu da se glavni interes usmjerava prema dopuni općeg znanja čitatelja s informacijama sadržanim u tekstu. Riječ je dakle o okupljanju informacija o književnim subjektima ili kontekstu radnje u pripovijesti. Tako okupljeno znanje Emmott (1997) naziva „Znanjem specifičnim za tekst“ koje je podložno preoblikama i ovisi o tome kako čitatelj napreduje u čitanju. ${ }^{15}$

U razvoju kognitivne naratologije pokazano je zanimanje za koncept pripovjednosti (narrativity) u onom shvaćanju što se u upotrebi preusmjerava od formalističkih ograničenja strukturalističke naratologije prema komunikacijskoj dimenziji pripovijesti. ${ }^{16} \mathrm{Na}$ primjer, Monice Fludernik (1996) pripovjednost rabi tako što sugerira da kognitivni parametri, oni tvorbeni pri prototipnom ljudskom iskustvu, predstavljaju glavni kriterij za ono što priču čini pričom, a ne tradicionalno smatran slijed događaja. Prema Fludernik mogu postojati pripovijesti bez radnje ( $p l o t$ ), ali ne bez ljudskog (antropomorfnog) doživljavača (experiencer).

Preoblikujući i nadopunjujući pojam imaginacije atributom pripovjednosti, Mark Turner s druge strane gradi tezu o literarnosti ljudskoga uma prema kojoj pripovijesti (parabole, parable) zrcale i osvjetljavaju procese stvaranja značenja u umu. ${ }^{17}$ Mnogi se slažu s tezom prema kojoj je svakodnevni ljudski um prven-

14 Bez takvih pohrana čitatelju ne bi bilo razvidno na primjer to da je osoba što istrčava iz banke, $s$ maskom preko lica, vjerojatno opljačkala banku.

15 Sličan koncept zastupa i Herman (2002).

16 Riječ je o onoj dimenziji koja razmatra međuodnos recepcije i same pripovijesti. 
stveno „književni“: iskustvo, znanje i razmišljanje ustrojeno je i organizirano kao pripovijest (usp. Culler 2002, Kearney 2009). Imaginativno djelovanje ljudskoga uma ostvaruje se upravo kroz priču kao glavni instrument procesa strukturiranja ljudskoga iskustva. Taj se proces promatra kao kontinuiran - svjesno se ili nesvjesno uspostavlja odnos između mentalnih predodžbi o predmetima, bićima i pojavama - što vodi uobličavanju i kreiranju složenih predodžbenih shema. Prema Turneru mentalni prostor pripovijesti uvećan je projekcijom jedna pripovijest pomaže nam shvatiti drugu, dati joj smisao, a projekcija jedne priče na drugu vrši se kroz parabolu. ${ }^{18}$ Pojedinčeve sposobnosti racionaliziranja, ističe Turner, ovise o književnom kapacitetu, on je neophodan za ljudsku spoznaju općenito. ${ }^{19}$ „Kao što je gledanje, reći će Turner, kontinuirano i samo po sebi pretpostavka da bismo išta vidjeli, tako je i konstruiranje priča kao mentalna aktivnost pretpostavka bilo kakvu pričanju, bilo kojem iskazu, zaključku ili stavu." (Biti, Marot Kiš, 2008: 35f) Na primjer, poslovice se mogu promatrati kao implicitne pripovijesti koje treba interpretirati kroz projekciju. ${ }^{20} \mathrm{U}$ slučajevima poput ovih ciljna domena/priča - ona koju trebamo razumjeti - nije ni spomenuta, međutim, kroz našu sposobnost da rabimo oboje, priču i projekciju, mi projiciramo izvornu priču na ciljnu priču. Uz kontekst, poslovica izgovorena u uredu, na primjer, može se projicirati na poslodavca i zaposlenike, ona u kontekstu seksualne veze može se projicirati na priču o nevjeri i slično. Takve projekcije kojima interpretiramo i konstruiramo značenje događaju se s tolikom lakoćom da nam se čini da ne činimo ništa. To je kao kada slušamo nečiji govor, navodi Turner, koristimo se kompliciranim i nesvjesnim znanjem da bismo razumjeli govor, ali nam se čini da smo pasivni, kao da slušamo, dok se razumijevanje zbiva kao kakvom magijom. Često kratka pripovijest neće sadržavati nikakvu vidljivu oznaku, osim onoga što tvrdi da prikazuje, no svejedno ćemo ju interpretirati kao projekciju koja se tiče mnogo veće i apstraktnije pripovijesti, one koja se može primijeniti na pojedini život bez obzira na to koliko je taj život zapravo udaljen od detalja pripovijesti. Ljudski um neprestano interpretira, na neki način prevodi stvarnost u različite vrste odnosa: prostornih, vremenskih,

1996: 6)

18 U hrvatskom jeziku parabola ima više značenja. Rabi se kao vrsta pjesničke figure u smislu usporedbe, ali i kao naziv za alegorijsku priču koja sadrži istinu ili nauk, priča u kojoj se usporedbom i prenesenim značenjem ilustrira moralna ili religiozna ideja. „Prijenos se pri tome zbiva prema načelu analogije: misaona poruka odgovara nekom događaju ili nekim odnosima u svakidašnjem životu." (Solar 2006: 210) To je prvi od načina na koji je ljudski um u suštini književni.

20 Turner navod primjer poslovice „Kada mačke nema, miševi kolo vode.“ (Turner 1996: 6) 
uzročno-posljedičnih ili drukčijih. Književna imaginacija ovdje služi kao primjena usvojenog iskustva na novo i nepoznato ili potencijalno, pri čemu nastaju novi konceptualno pretopljeni mentalni prostori kao i nova, drukčija značenja (usp. Biti, Marot Kiš 2008: 110). Poopćeno, ako želimo proučavati svakodnevni um, trebamo se okrenuti književnom umu upravo stoga što je svakodnevni um u suštini književni.

Pripovijest kao mentalnu aktivnost Turner drži esencijalnom ljudskoj misli tvrdeći da su osnovne ili bazične pripovijesti što ih najbolje poznajemo zapravo male priče zbivanja u prostoru (small stories of events in space). Njih - zbog esencijalnog karaktera i sveprisutnosti - često ne primjećujemo, ali ljudski um neprestano oblikuje te male priče koje svakodnevni život čine mogućim i koje stvaraju iskustvo. Kada pojedinac ne bi imao te „male priče“, raspoloživo iskustvo bilo bi kaotično (usp. Turner 1996). Turnerova, i ranije spomenute studije dio su prvih obuhvatnijih pristupa što zadiru u vezu uma i pripovijesti. Godinu dana prije Turnerove, objavljena je zbirka tekstova Deixis in Narrative ${ }^{21}$ u kojoj različiti autori problematiziraju razumijevanje pripovijesti kroz termine deiktičkih pomaka, bilo premještanjem interpretatorovih prostorno-vremenskih koordinata „ovdje i sada“ do različitih kognitivnih pozicija koje su oni u mogućnosti zauzeti zbog tekstualnih signala razmještenih u pripovjednome diskursu.

Pristupi koji se bave vezom uma i pripovijesti kontinuirano se i dalje pojavljuju, razvijaju i interferiraju, te se dijelom uključuju u kognitivno-naratološka istraživanja. S druge strane, različiti naratološki pravci, teorije i metode što su se razvili od osamdesetih i devedesetih godina naovamo svjedoče o relevantnosti naratologije uopće, tako i kognitivne naratologije, što je dobrim dijelom posljedica njezina interdisciplinarna karaktera. Svaka pojedina disciplina uključuje metodologiju i pojmove drugih disciplina otvarajući mogućnost za produktivniju i otvoreniju analizu. Kao što primjećuje Shang, naratološki su pravci komplementarni: „kognitivna naratologija može biti od pomoći feminističkoj naratologiji i retoričkoj naratologiji s prednostima što proizlaze iz teorija scenarija, okvira, shema i mentalnih modela, pri analizi uloga narativnih konvencija i općenito publike u pripovjednoj strukturi jednako kao i u razumijevanju pripovijesti." (Shang 2011: 141) Zbog razvoja teorije uma, kao i sve brojnijih istraživanja vezanih za spregu uma i pripovijesti, teško je pretpostaviti što će pružiti 
najupečatljivije doprinose u razvoju naratologije. Neka od relevantnih područja istraživanja jesu ona pripovjedne perspektive iz kognitivne vizure u fikcionalnim i nefikcionalnim tekstovima, zatim istraživanja koja se tiču reprezentacije uma književnih subjekata i tekstualnih znakova što čitateljima omogućuju donošenje određenih zaključaka o sadržaju, zatim proučavanja emocija te njihov doprinos recepciji tekstova, istraživanja intermedijalnosti koja pokušavaju ukazati na to da pripovijest djeluje kao kognitivni makrookvir, što omogućuje tumačenje i identifikaciju priča ili dijelova nalik priči kroz različite (tekstualne, slikovne, glazbene, izvedbene...) medije.

\section{Literatura}

Belaj, Branimir; Tanacković Faletar, Goran. 2006. Protučinjenične uvjetne rečenice, mentalni prostori i metonimija u kontekstu teorije konceptualne integracije. Suvremena lingvistika 62, 2, 151-181.

Biti, Marina; Marot Kiš, Daniela. 2008. Poetika uma: Osvajanje, propitivanje i spašavanje značenja. Rijeka: Izdavački centar Rijeka.

Biti, Marina; Marot Kiš, Daniela. 2014. Konceptualna metafora i kognitivna poetika. U: Stanojević, Mateusz-Milan (ur.): Metafore koje istražujemo. Suvremeni uvidi u konceptualnu metaforu. Zagreb: Srednja Europa, 203-231.

Culler, Jonathan 2001. Književna teorija - vrlo kratak uvod. Zagreb: AGM.

Emmott, Catherine 1997. Narrative Comprehension: A Discourse Perspective. Oxford: Oxford UP.

Fludernik, Monica 1996. Towards a "Natural" Narratology. London: Routledge.

Herman, David. 1997. "Scripts, Sequences, and Stories: Elements of a Postclassical Narratology”. PMLA 112, 1046-1059.

Herman, David 1999. Narratologies: New Perspectives on Narrative Analysis. Columbus: Ohio State University Press.

Herman, David. 2002. Story Logic: Problems and Possibilities of Narrative. Lincoln: University of Nebraska Press.

Herman, David. 2005. Routledge Encyclopedia of Narrative Theory. London, New York: Routledge.

Herman, David. 2000. "Narratology As a Cognitive Science". Online Magazine of the Visual Narrative, 1-18.

Jahn, Manfred. 1996. "Windows of Focalisation: Deconstructing and Reconstructing a Narratological Concept." Style 30, 241-67.

Kearney, Richard 2009. O pričama. Zagreb: Jesenski i Turk.

Lakoff, George; Johnson, Mark. 1999. Philosophy in the Flesh. New York: Basic Books.

Meister, Jan Christoph. 2009. "Narratology”. U: Handbook of Narratology, Narratologia 19, Berlin, New York, 329-351. 
Nünning, Ansgar. 2003. “Narratology or Narratologies?” U: Kindt, T. i Müller, H. (ur.): What is Narratology. Berlin, New York: De Gruyter, 239-275.

Peternai Andrić. 2014. Kontekstualnost i interdisciplinarnost suvremene naratologije. Književna smotra XLVI, 171 (1), 31-36.

Pier, John. 2011. “Is There a French Postclassical Narratology?” U: Olson, G. (ur.): Current Trends in Narratology. Berlin, New York: De Gruyter.

Shang, Biwu, 2011. "Plurality and Complementarity of Postclassical Narratologies." Journal of Cambridge Studies 6, 132-147.

Spolsky, Ellen 2002. "Darwin and Derrida: Cognitive Literary Theory As a Species of Post-Structuralism”. Poetics Today 23, 1, 43-62.

Stanojević, Mateusz-Milan (ur). 2014. Metafore koje istražujemo. Suvremeni uvidi u konceptualnu metaforu. Zagreb: Srednja Europa.

Stockwell, Peter. 2002. Cognitive Poetics: Introduction. New York: Routledge.

Stockwell, Peter. 2007. "Cognitive Poetics and Literary Theory". Journal of Literary Theory $1(1), 135-52$.

Turner, Mark. 1996. The literary mind. New York: Oxford University Press.

Vandaele, Jeroen; Brône, Geert. 2009. Cognitive Poetics: Goals, Gains and Gaps. Berlin, New York: Mouton de Gruyter.

Van Dijk, Teun A. 2006. Ideologija: Multidisciplinaran pristup. Zagreb: Golden marketing Tehnička knjiga.

\section{Literatura s mrežnih stranica}

Alexander, Marc \& Emmott, Catherine. 2011. Schemata. U: Hühn, Peter (ur.): The Living Handbook of Narratology. Hamburg: Hamburg University. URL: http://www.lhn. uni-hamburg.de/article/schemata (6. 4. 2017.)

Herman, David. 2013. Cognitive Narratology. U: Hühn, Peter (ur.): The Living Handbook of Narratology. Hamburg: Hamburg University.

URL: http://www.lhn.uni-hamburg.de/article/cognitive-narratology-revised-version-uploaded-22-september-2013 (24. 8. 2016.) 


\title{
THE SPHERE OF COGNITIVE NARRATOLOGY
}

\begin{abstract}
Kristina PETRNAI ANDRIĆ

Faculty of Humanities and Social Sciences

Josip Juraj Strossmayer University of Osijek

Lorenza Jägera 9, HR - 31000 Osijek

kpeterna@ffos.hr

Viktoria KLUISER

Ružina 51b, HR - 31327 Vardarac

viktoriakluiser@gmail.com

The paper thematizes cognitive narratology as a direction developed within postclassical and new narratologies by observing it in a series of related concepts such as cognitive poetics, cognitive linguistics, cognitivism, and evolutionary literary theory. It delineates its scope and reach within cognitive science, and discusses concepts such as schemata, frames, narrativity, parables, and others, which can influence the development and transformation within cognitive narratology.
\end{abstract}

Keywords: Cognitive narratology, cognitive poetics, schema, frame, narrativity 